\title{
RESTRIÇÕES E PREFERÊNCIAS ALIMENTARES EM COMUNIDADES DE PESCADORES DO MUNICÍPIO DE CONDE, ESTADO DA BAHIA, BRASIL'
}

\section{FOOD AVOIDANCES AND PREFERENCES AMONG FISHERMEN COMMUNITIES FROM THE COUNTY OF CONDE, STATE OF BAHIA, BRAZIL}

Eraldo Medeiros COSTA-NETO2

\begin{abstract}
RESUMO
Restrições e preferências de recursos pesqueiros por pescadores do município de Conde, Norte do estado da Bahia, são analisadas. Dados foram obtidos através de entrevistas abertas e semi-estruturadas realizadas com 114 informantes de cinco comunidades. Peixes, moluscos, crustáceos, cetáceos e tartarugas marinhas são recursos disponíveis aos pescadores, que percebem aspectos marcantes desses animais no momento de considerá-los itens comestíveis. Peixes de "couro", como arraias e cações, são os mais evitados durante enfermidades, enquanto peixes "brancos", como os robalos, são as espécies mais preferidas. Muitos desses recursos são também usados na medicina popular local. O comportamento alimentar dos pescadores deveria ser levado em consideração no planejamento ambiental, em estudos de impacto ambiental e no manejo, conservação e monitoramento dos recursos pesqueiros.
\end{abstract}

Termos de indexação: tabus alimentares, recursos pesqueiros, comportamento alimentar, pescadores brasileiros.

\begin{abstract}
Fishing resources avoidances and preferences of fishermen from the county of Conde, in the North of the State of Bahia, are analyzed. Data were obtained through open-ended and semi-structured interviews performed with 114 informants from five communities. Fish, mollusks, crustaceans, cetaceans and sea turtles are available resources for the fishermen. They perceive remarkable aspects of these animals when considering them as edible items. "Leather" fish such as rays and sharks are the most avoided during illnesses, and "white" fish such as snooks are the most preferred species. Many of these resources are also used in the local folk medicine. Fishermen's feeding behavior should be taken into account for the development planning and environmental assessment studies, as well as the management, conservation and monitoring procedures of fishing resources.
\end{abstract}

Index terms: food taboos, fishing resources, feeding behavior, brazilian fishermen.

(1) Trabalho elaborado a partir da dissertação de mestrado em Desenvolvimento e Meio Ambiente: "Etnoictiologia, desenvolvimento e sustentabilidade no litoral norte baiano. Um estudo de caso entre pescadores do município de Conde", defendida na UFAL, Maceió, Alagoas, em outubro de 1998.

(2) Departamento de Ciências Biológicas, Universidade Estadual de Feira de Santana, Km 3, BR 116, Av. Universitária, 44031-460, Feira de Santana, BA, Brasil.Correspondência para/Correspondence to: E.M.COSTA-NETO.E-mail: eraldont@uefs.br 


\section{INTRODUÇÃO}

"Tabus alimentares representam regras sociais não escritas que regulam o comportamento humano".

Colding \& Folk (1997)

Os peixes são recursos do ambiente percebidos e explorados de acordo com os termos culturais próprios de cada sociedade (Mitchell, 1989). Muitas das espécies de peixes têm ao menos algum valor de mercado direto ou fazem parte de teias alimentares que suportam outros recursos economicamente importantes. Os recursos pesqueiros proporcionam satisfações estéticas (Moyle \& Cech Jr., 1996) e têm sido fonte de substâncias naturais de interesses diversos, principalmente farmacológicos (Norse, 1993).

No que se refere à utilização dos peixes como recursos alimentares, preferências e evitações ao seu consumo têm sido o assunto de muitos estudos na Antropologia e na Ecologia Humana (Bulmer et al., 1975; Hyndman, 1984; Begossi \& Braga, 1992; Castelo Branco \& Begossi, 1996; Murrieta, 1998). Geralmente, a evitação a peixes é simplesmente uma questão de indiferença ou leve desaprovação pelo ato de ingeri-los. Em outros, no entanto, verifica-se uma forte objeção ao seu consumo (Simoons, 1978). Begossi (1992) encontrou que recursos ícticos valorizados na medicina popular são considerados tabus alimentares (hipótese da farmácia).

O entendimento de como os indivíduos em comunidades humanas procuram, obtêm e escolhem o alimento, incluindo o tipo de tecnologia associado ao ambiente ocupado, é fundamental para a compreensão dos valores culturais e relações sociais (Begossi \& Petrere Jr., 1988). Segundo Bahuchet (1997), a alimentação é um domínio relevante às ciências biológicas e sociais, suscetível de quantificação precisa, mas profundamente marcada pela cultura. De acordo com esse autor, o comportamento alimentar constitui um dos modos pelos quais uma sociedade afirma sua coesão através, por exemplo, dos tabus ou preferências gustativas. Hyndman (1984) diz que a etnoclassificação dos alimentos influencia os sistemas tradicionais de subsistência porque define o que deve ser considerado alimento, classificando-o em uma escala de preferências e ditando tanto a intensidade quanto a freqüência com que as espécies são caçadas, pescadas e/ ou cultivadas.

Este artigo pretende registrar a percepção e a utilização de recursos pesqueiros pelos pescadores do município de Conde, Bahia, analisando os aspectos associados à evitação ou à incrementação de seu consumo. Chama-se atenção para a inclusão de estudos sobre antropologia do alimento no planejamento ambiental, em estudos de impacto ambiental e no manejo, conservação e monitoramento dos recursos pesqueiros.

\section{Área de estudo}

O município de Conde situa-se na Região Litoral Norte do estado da Bahia, cujas coordenadas geográficas são $11^{\circ} 48^{\prime} \mathrm{S}$ e $37^{\circ} 37^{\prime} \mathrm{W}$ (Figura 1). A região apresenta um clima úmido a subúmido e úmido, uma temperatura média de $25,4^{\circ} \mathrm{C}$, uma pluviosidade anual média de 1412 mm e uma vegetação constituída de formações pioneiras com influência fluviomarinha (mangue) arbórea, formações pioneiras com influência marinha (restinga) arbórea e contato cerrado-floresta estacional (Centro..., 1994).

Com aproximadamente $40 \mathrm{Km}$ de litoral, a região possui duas desembocaduras: a Barra do Rio Itapicuru, ao norte, e a Barra do Rio Itariri, ao sul. Vários povoados formam o município, como Altamira, Cobol, Cangurito, Barra do Itariri, Sítio do Conde, Poças e Siribinha, sendo os quatro últimos de interesse recreativo por estarem situados no litoral. Devido à sua importância no cenário paisagístico-ecológico e social, a região foi transformada em uma Área de Proteção Ambiental em março de 1992.

A economia do município baseia-se no comércio, prestação de serviços e extrativismo, com destaque para: indústrias de pequeno porte, tais como madeireiras, perfumarias, sabões e velas, tecidos e produtos alimentares; culturas agrícolas, como coco-da-bahia, banana, mamão, limão, arroz, mandioca, tomate e milho; criação de gado bovino e pesca e mariscagem. Estas duas últimas atividades sobressaem-se devido ao fornecimento significativo de recursos pesqueiros. No município de Conde, a produção de pescado nos anos de 1992/1993 foi de $23426 \mathrm{~kg}$, distribuídos em $17920 \mathrm{~kg}$ de peixes e $5506 \mathrm{~kg}$ de crustáceos (Bahia, 1994). Atualmente, o turismo e a construção civil passaram a desempenhar atividades importantes para a região e para os moradores locais desde a implantação da Linha Verde, rodovia estadual inaugurada em dezembro de 1993.

\section{MATERIAL E MÉTODOS}

O trabalho de campo teve início em março de 1996 e foi concluído em março de 1998. Nesse período, cerca de 10 excursões à área de estudo foram realizadas, totalizando 56 dias de trabalho de campo. Foram entrevistados 114 informantes, distribuídos, segundo a comunidade em que residem, da seguinte forma: Barra do Itariri, 3 informantes; Conde, 8 informantes; Sítio do Conde, 14; Poças, 5 e Siribinha, 84. No início, os dados foram obtidos por meio de entrevistas abertas, adotando-se expressões e palavras nativas. As entrevistas duraram cerca de poucos minutos a duas horas. Elas foram registradas por escrito e/ou eletromagneticamente. As fitas correspondentes às 15 horas de entrevistas gravadas foram transcritas e encontram-se depositadas no Laboratório de Etnobiologia da Universidade Estadual de Feira de Santana. (UEFS). As cenas culturais, a atividade de pesca, os atores 
sociais e os recursos faunísticos foram registrados fotograficamente, tanto por meio de diapositivos quanto por meio de fotos em papel, os quais também encontram-se compondo o acervo do referido Laboratório.

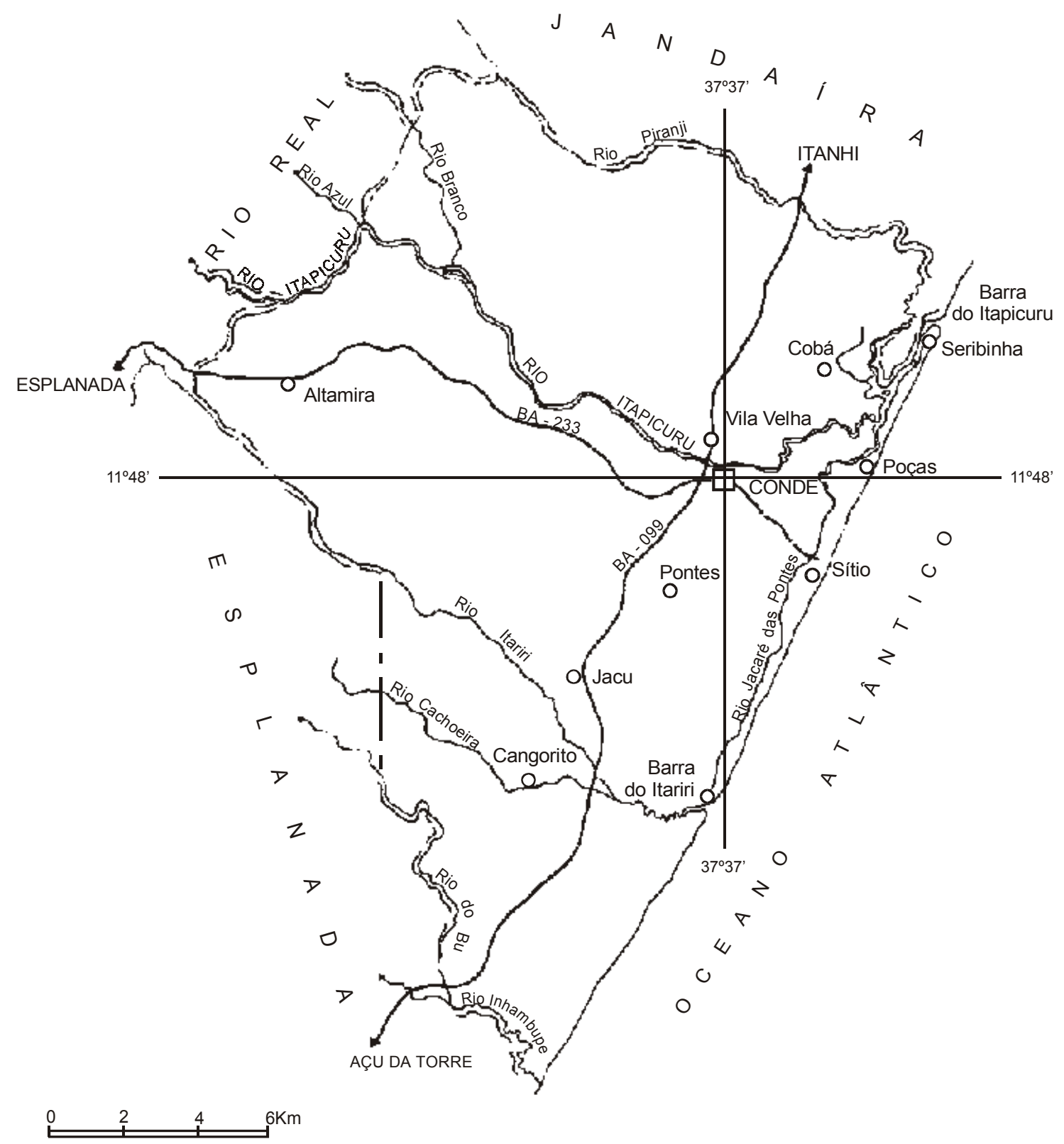

Figura1. Localização da comunidade pesqueira estuda. 
Às entrevistas livres, seguiram-se entrevistas semi-estruturadas baseadas em questionários semi-estruturados e em uma lista contendo os nomes vernaculares de 69 peixes, inclusive os de uso medicinal, com os quais se obteve dados sobre a interação trófica e as intervenções alimentares envolvendo as diversas espécies. Neste artigo, os nomes populares dos peixes foram escritos tal como são denominados pelos informantes.

Os dados foram analisados segundo o modelo de união das diversas competências individuais (Marques, 1991), o qual consiste em considerar todas as informações fornecidas por todos os entrevistados, sem exclusão. Segundo Marques (1991), a tendência em trabalhos etnocientíficos tem sido pela obtenção desse modelo. Os controles foram feitos através de testes de verificação de consistência e de validade das respostas, recorrendo-se a entrevistas repetidas em situações sincrônicas e diacrônicas. As primeiras ocorrem quando uma mesma pergunta é feita a pessoas diferentes em tempo bastante próximo e as segundas, quando uma pergunta é repetida à mesma pessoa em tempos bem distintos (Marques, 1991).

Foram coletadas 57 espécies de peixes, constituindo-se esta coleção apenas em uma representação parcial da diversidade ictiofaunística da região. Algumas espécies foram compradas pelo autor na feira do Conde, mas a maioria foi doada pelos pescadores de Siribinha. Os espécimes, identificados pelo professor Paulo Roberto Duarte Lopes do Departamento de Ciências Biológicas da UEFS, encontram-se depositadas na coleção científica do Laboratório de Ictiologia do Departamento. Os espécimes de crustáceos foram identificados pela professora Tereza Calado (Departamento de Zoologia do Centro de Ciências Biológicas da Universidade Federal de Alagoas) e estão depositados no Laboratório de Etnobiologia da UEFS.

\section{RESULTADOS E DISCUSSÃO}

As comunidades de pescadores artesanais do Litoral Norte baiano podem utilizar-se de diferentes recursos faunísticos, quer seja consumindo-os diretamente, quer seja comercializando-os para obtenção de outros recursos, como carne vermelha, produtos vegetais e enlatados. De um modo geral, os recursos pesqueiros localmente utilizáveis como alimento constituem-se de peixes, crustáceos, moluscos, cetáceos (toninhas) e quelônios marinhos (tartarugas). Estes dois últimos, segundo os informantes, são consumidos apenas quando pescados acidentalmente. A dieta é complementada através da caça de mamíferos (e.g., tatus, preás e cutias), aves (garças, jacus e frangos-d'água) e répteis (lagartos, cobras e jacarés). Estes recursos, no entanto, caracterizam-se como fonte renovável de proteína de natureza alternativa e secundária. Méis silvestres também são consumidos, especialmente os que são extraídos de colmeias de abelhas italianas (Apis mellifera scutellata), constituindo-se fonte secundária de carboidratos.

De significativa importância para o suprimento das necessidades alimentares da população local são os peixes, os quais constituem-se em recursos amplamente distribuídos em toda a região, destacando-se os das famílias Sciaenidae (curvinas), Gerreidae (carapebas), Mugilidae (tainhas), Centropomidae (rubalos), Ariidae (bagres), Engraulididae (sardinhas) e Carangidae (xaréus). O modo como estes recursos são percebidos, classificados e utilizados influencia tanto na intensidade quanto na freqüência com que as espécies de peixes são pescadas, tratadas e consumidas.

Nas comunidades pesqueiras, a refeição usual é constituída de peixe frito ou cozido, arroz, feijão de coco, farinha de mandioca (localmente produzida ou comprada em comunidades próximas), pirão (feito com o caldo no qual se cozinha o peixe), salada (composta de tomate, cebola e alface frescos) e, às vezes, macarrão, carne de boi ou frango. Não obstante a importância do pescado para as famílias locais, algumas regras relacionadas à restrição ou incrementação de seu consumo foram observadas.

Com base nos dados obtidos, um conjunto de 69 tipos de peixes, representados por diferentes espécies, foram citados quanto a sua comestibilidade (Tabela 1). As espécies que são utilizadas na medicina popular $(n=24)$ foram analisadas separadamente com o objetivo de destacar a sua participação na dieta dos moradores locais (Tabela 2). Segundo os informantes, as razões listadas para se aceitar ou se evitar o consumo de pescado variaram entre as espécies. De um modo geral, os pescadores levam em consideração as características comportamentais, morfológicas, toxicológicas, odoríferas e alimentares dos peixes prescritos como alimentos. Por exemplo, parecerse com cobras e possuir dentes são motivos que restringem o consumo de certos peixes, como o muçum (Synbranchus marmoratus), o cramuru (Muraenidae) e a mututuca (Ophichthidae). A similaridade com cobras, contudo, parece não constituir um limite para o consumo de peixes ofidiomorfos em outras culturas pesqueiras. Para os Karam, por exemplo, as enguias são muito valorizadas como alimento e para a cozinha ritual (Bulmer et al., 1975).

A quantidade de espinhas também foi citada como um dos fatores que limitam o consumo de peixes, especialmente pelas crianças ("cangurupim (Tarpon atlanticus) tem muita espinha"). Segundo o nível de consumo, os peixes podem ser classificados em quatro categorias: peixes consumidos com restrições; peixes consumidos sem restrições; peixes pouco ou quase nunca consumidos e peixes que não têm utilidade alimentar. A comestibilidade das espécies de peixes depende tanto do estado de saúde e das condições físicas de seus consumidores, quanto dos efeitos que a sua ingestão acarreta. As categorias de consumidores reconhecidas pelos informantes foram: "mulher grávida", "mulher parida", "mulher de resguardo", "pessoas com ferimentos", "pessoas operadas", "pessoas com problemas de vista", "pessoas doentes", "quem fez trabalho de canzoá (candomblé)", "quem é rezado de espinhela caída", "quem conhece (o peixe a ser consumido)", "quem não conhece", "quem sabe preparar" e "todo mundo". Estas categorias de consumidores podem ser divididas em dois grupos: "o dos que podem" e "o dos que não podem" alimentar-se de peixes e outros pescados, como crustáceos e moluscos, em períodos curtos ou longos de sua vida. 
Tabela 1. Peixes utilizados como recursos alimentares por pescadores do município de Conde (BA), classificados segundo o nível de consumo.

\begin{tabular}{|c|c|c|c|c|}
\hline Nome vulgar & Taxonomia & Categoria de consumidores & Motivo & Observação \\
\hline \multicolumn{5}{|c|}{ Peixes consumidos com restrição } \\
\hline Caranha & Lutjanus sp. & Pessoas doentes & Carregado & $\ldots$ \\
\hline Capadinho & & Mulher de resguardo & Idem & $\ldots$ \\
\hline Corró-paru & Chaetodipterus faber & $\begin{array}{l}\text { Pessoa que faz trabalho de canzoá } \\
\text { (candomblé) }\end{array}$ & Quebra a seita & $\ldots$ \\
\hline Cumbá & Parauchenipterus galeatus & Mulher parida e pessoas doentes & Carregado & $\ldots$ \\
\hline Dourado & Coryphaena hippurus? & Idem & Idem & $\ldots$ \\
\hline Guaricema & Caranx sp.? & Pessoas enfermas & Idem & $\ldots$ \\
\hline Jundiá & Rhamdia sp.? & Idem & Idem & $\ldots$ \\
\hline Mandi & Pimelodus sp. & Mulher parida e pessoas com ferimentos & s Idem & $\ldots$ \\
\hline Peloque & 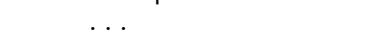 & Mulher parida e pessoas doentes & Idem & $\ldots$ \\
\hline Peixe-prego & Ruvettus pretiosus? & Idem & Idem & Causa diarréia \\
\hline Piranha & Serrasalmus cf. piraya & Mulher de resguardo & Idem & $\ldots$ \\
\hline Roncador & Conodon nobilis & Mulher parida & Idem & $\ldots$ \\
\hline Sororoca & Trichiurus sp.? & Mulher de resguardo & Carregado & $\ldots$ \\
\hline $\begin{array}{l}\text { Tainha-olho-de- } \\
\text {-fogo }\end{array}$ & Mugil sp. & Mulher grávida ou parida & Carregada & $\ldots$ \\
\hline Traíra-canguçu & Hoplias lacerdae? & Quem é rezado de espinhela caída & Raceia com a cobra jaracuçu & $\ldots$ \\
\hline Traíra-do-mar & Synodus foetens & Mulher parida & Carregada & $\cdots$ \\
\hline Ubarana & Elops saurus & Mulher de resguardo & Idem & $\ldots$ \\
\hline Xaréu & Caranx spp. & $\begin{array}{l}\text { Pessoa que faz trabalho de canzoá } \\
\text { (candomblé) }\end{array}$ & Quebra a seita & $\begin{array}{l}\text { Considerado como } \\
\text { peixe de couro }\end{array}$ \\
\hline \multicolumn{5}{|c|}{ Peixes consumidos sem restrição } \\
\hline Barbudo-do-mar & Polydactylus virginicus & Todo mundo & Descarregado & \\
\hline Carapeba & Diapterus rhombeus & Idem & Idem & Peixe de resguardo \\
\hline Cariocó & $\ldots$ & Idem & Idem & $\ldots$ \\
\hline Dentão & Lutjanus aya? & Idem & Idem & \\
\hline Gorana & $\ldots$ & Idem & Idem & \\
\hline Guaiúba & Ocyurus chrysurus & Idem & Idem & $\ldots$ \\
\hline Pescada & Larimus breviceps & Idem & Idem & Peixe de resguardo \\
\hline Pescadinha & Cynoscion microlepidotus & Idem & Idem & $\ldots$ \\
\hline Rubalo & Centropomus spp. & Idem & Idem & Peixe de resguardo \\
\hline Rubalo-branco & Centropomus parallelus & Idem & Idem & Idem \\
\hline Rubalo-preto & Centropomus sp. & Idem & Idem & Idem \\
\hline Sardinha & Anchovia clupeoides & Idem & Idem & $\ldots$ \\
\hline Saúna-de-fogo & Mugil sp. & Todos comem & Descarregada & $\ldots$ \\
\hline Tainha & Mugil curema & Idem & Descarregada & $\ldots$ \\
\hline Tainha-olho-preto & Mugil sp. & Idem & Descarregada & $\ldots$ \\
\hline Vermelho & Lutjanus analis & Idem & Descarregada & $\ldots$ \\
\hline \multicolumn{5}{|c|}{ Peixes pouco ou quase nunca consumidos } \\
\hline Aramaçá & Citharichthys sp. & & & \\
\hline Baiacu-mirim & Sphoeroides testudineus & Todo mundo & Venenoso & $\ldots$ \\
\hline Cação-sombreiro & Isurus oxyrinchus? & & & \\
\hline Cramaru & Gymnothorax vicinus? & Tem gente que come & Parece com cobra & $\ldots$ \\
\hline Eiú & Hoplerythrinus unitaeniatus? & Idem & Come carniça & $\begin{array}{l}\text { Gerado das fezes do } \\
\text { gado }\end{array}$ \\
\hline Lampréia & Gymnotus sp. & Idem & Parece com cobra & $\ldots$ \\
\hline Moréia & Muraena helena? & Idem & Idem & $\ldots$ \\
\hline Mututuca & Gymnothorax ocellatus ? & Idem & Idem & $\ldots$ \\
\hline Peixe-macaco & Scartella cristata & Idem & Fede demais & $\begin{array}{l}\text { Só tem na Praia de } \\
\text { Poças }\end{array}$ \\
\hline Peixe-sabão & Rypticus sp. & Idem & Desliza muito & $\ldots$ \\
\hline \multicolumn{5}{|c|}{ Peixes nunca consumidos } \\
\hline Papa-loba & Poecilia cf. vivipara & Todo mundo & $\begin{array}{l}\text { Tem fel na } \\
\text { barriga/tem verme }\end{array}$ & A barriga incha \\
\hline
\end{tabular}


Tabela 2. Peixes medicinais utilizados como recursos alimentares por pescadores do município de Conde (BA), classificados segundo o nível de consumo.

\begin{tabular}{|c|c|c|c|c|}
\hline Nome vulgar & Taxonomia & Categoria de consumidores & Motivo & Observação \\
\hline \multicolumn{5}{|c|}{ Peixes consumidos com restrição } \\
\hline Arraia & Myliobates sp. & $\begin{array}{l}\text { Mulher parida, de resguardo e } \\
\text { pessoas com ferimentos }\end{array}$ & Carregada & Peixe de couro \\
\hline Bagre-fidalgo & Bagre bagre & Idem & Idem & Idem \\
\hline Bagre-urutu & Sciadeichthys luniscutis & Tem gente que come & Venenoso & $\ldots$ \\
\hline Caboge & Callichthys cf. callichthys & Todo mundo & Carregado, nojento & Tem casco \\
\hline Cação-gaia-preta & Carcharhinus porosus & $\begin{array}{l}\text { Mulher parida, de resguardo e } \\
\text { pessoas com ferimentos }\end{array}$ & Carregado & $\ldots$ \\
\hline Cação-panã & Sphyrna lewini & Idem & Idem & \\
\hline Cação-rabo-seco & Rhizoprionodon sp. & Idem & Idem & \\
\hline Cangurupim & Tarpon atlanticus & Pessoas operadas & Carregado & Tem muita espinha \\
\hline Capado & Balistes vetula & Pessoas enfermas & Idem & $\ldots$ \\
\hline Rubalão & Centropomus undecimalis & Mulher de resguardo & Idem & $\ldots$ \\
\hline Traíra & Hoplias malabaricus & $\begin{array}{l}\text { Mulher de resguardo e pessoas } \\
\text { enfermas }\end{array}$ & Idem & $\ldots$ \\
\hline \multicolumn{5}{|c|}{ Peixes consumidos sem restrição } \\
\hline Bacalhau & Gadus sp. & Todo mundo come & Descarregado & $\ldots$ \\
\hline Bagre-do-mangue & Netuma barba & Mulher de resguardo & Idem & É mais limpo \\
\hline Bonome & Haemulon sp & Todo mundo come & Descarregado & $\ldots$ \\
\hline Curvina & Micropogonias furnieri & Idem & Idem & Peixe de resguardo \\
\hline Peixe-pena & Calamus penna? & Idem & Idem & $\ldots$ \\
\hline Piaba-mirim & Astyanax cf. bimaculatus & Idem & Idem & $\ldots$ \\
\hline Xira & Prochilodus sp. & Idem & Idem & $\ldots$ \\
\hline \multicolumn{5}{|c|}{ Peixes pouco ou quase nunca consumidos } \\
\hline Baiacu-xaréu & Colomesus sp. & Tem gente que come & Venenoso & $\ldots$ \\
\hline Muçum & Synbranchus marmoratus & Idem & Descarregado & Parece com cobra \\
\hline Niquim & Thalassophryne nattereri & Idem & Venenoso & $\cdots$ \\
\hline Pegador & Echeneis naucrates & Idem & Descarregado & $\ldots$ \\
\hline Peixe-elétrico & Narcine brasiliensis & Idem & Dá choque & Espuma na panela \\
\hline \multicolumn{5}{|c|}{ Peixes nunca consumidos } \\
\hline Cavalo-marinho & Hippocampus heidi & Todo mundo & Não tem carne & Casco puro \\
\hline
\end{tabular}

As qualidades dietéticas dos peixes percebidas pelos pescadores constituem um dos modos de classificarem as espécies. Dos peixes listados, 18 foram incluídos na etnocategoria dos "peixes carregados"; 17 foram reconhecidos como "peixes descarregados" ou "peixes brancos"; 3 foram citados como "peixes venenosos", enquanto outros 3 foram incluídos na etnocategoria dos "peixes nojentos" e 2 foram citados como "peixes imundos". Segundo a percepção de alguns informantes, o caboge (Callichthys cf. callichthys) é considerado o "primeiro peixe mais imundo", pois acreditam que ele se origine dos excrementos do gado. Os bagres, em sua maioria, são categorizados como "peixes nojentos" por alimentarem-se de fezes humanas "fedentina". As arraias e os cações foram considerados como "peixes carregados", enquanto que carapebas e pescadas são "peixes descarregados".

$\mathrm{Na}$ percepção dos entrevistados, os peixes apontados como os mais evitados foram: arraias (Mylobates sp.), capado (Balistes vetula), bagres (Bagre bagre), cações (Carcarhinus porosos), traíra (Hoplias malabaricus) e cangurupim (Tarpon atlanticus). Estes itens alimentares são principalmente evitados por pessoas enfermas ou que apresentam ferimentos no corpo, assim como aquelas que se recuperam de operações e "mulheres paridas", as quais são proibidas de consumir estes e outros alimentos 
considerados "carregados" ou "remosos". Das espécies citadas acima, elasmobrânquios (arraias e cações) e bagres são conhecidos e classificados como "peixes de couro", termo comumente utilizado para caracterizar as espécies "carregadas". No sistema trófico-cultural percebido e desenvolvido pelos pescadores de Siribinha, no entanto, uma espécie de bagre (bagre-do-mangue, Netuma barba) foi considerada como "peixe descarregado", apesar de ter sido incluída na etnocategotia dos "peixes imundos". É válido mencionar que, segundo dados sobre a ecologia trófica dos peixes obtidos com os informantes, os peixes mencionados como os de uso mais restritivos possuem hábito alimentar carnívoro, alimentando-se especialmente de outros peixes.

De acordo com Begossi (1992), comunidades que têm o peixe como principal fonte de proteína animal apresentam tabus relacionados a espécies consideradas remosas. Uma característica do peixe remoso é que esse poderia engrossar o sangue e exacerbar alguns problemas de saúde dos consumidores (Begossi \& Braga, 1992; Madi \& Begossi, 1996). No Rio Tocantins, peixes de couro são evitados porque são remosos ou porque têm "carne forte" (Begossi \& Braga, 1992). Em uma vila de pescadores do Rio Piracicaba, SP, o caborja (Hoplosternum litoralle) não é consumido por $80 \%$ dos moradores pelo mesmo motivo (Castelo Branco \& Begossi, 1996). Em Búzios, mulheres não podem consumir peixes carregados durante o período de menstruação ou após terem dado à luz (Begossi, 1992). Ao longo do Rio Madeira, a piraíba (Brachyplatystoma filamentosum) e o mapará (?) são acreditados transmitir lepra, enquanto que o jaú (Paulicea luetkeni) é evitado, pois acredita-se que provoca hemorróidas e abortos (Smith, 1985). Este autor afirma que a aversão a comer bagres provém das culturas indígenas. Os Piaroa classificam os peixes e outros animais com base nos tabus alimentares e elementos religiosos (Royero, 1989). Os Camaiurá, que habitam o estado do Mato Grosso, consideravam "reimosos" (prejudiciais ao sangue) os peixes lisos e as mulheres grávidas não podiam comê-los (Morán, 1990). Os Kayapó que vivem no estado do Pará não consomem peixe cru, pois acreditam que acarretam doenças (Petrere Jr, 1990). Os índios Wayana, também do Pará, abstêm-se de comer peixes vermelhos, de carne amarela ou reconhecidamente vorazes quando apresentam feridas, hemorragias ou quando as mulheres estão em período de resguardo (Van Velthen, 1990).

A noção de que espécies de peixes evitadas como recursos alimentares relacionam-se àquelas usadas na medicina popular deu origem à hipótese da farmácia (Drugstore hypothesis) segundo a qual, "peixes considerados importantes no tratamento de doenças de populações isoladas podem ser interditados para estar disponíveis à medicina popular" (Begossi, 1992). Como Begossi (1992) e Begossi \& Braga (1992) observaram, a utilidade de peixes na medicina caseira e os hábitos piscívoros da maioria dos peixes citados como não consumidos, parcialmente explicam as escolhas alimentares dos pescadores que habitam a Ilha de Búzios e as margens do Rio Tocantins, respectivamente. Em Siribinha, no entanto, espécies ictiófagas tanto são consumidas quanto são evitadas como recursos alimentares, assim como os peixes de uso medicinal (com exceção daqueles que não possuem "carne", como os cavalos-marinhos) parecem ser pescados e consumidos indistintamente de seu valor terapêutico, concorrendo, para isso, a sua disponibilidade, sua abundância, sua captura, bem como a preferência pessoal pela sua carne.

Assim como há peixes de consumo alimentar restrito, existem aqueles considerados livres de interdições, os quais são percebidos e classificados como "peixes brancos" ou "peixes descarregados" e que podem ser consumidos por pessoas enfermas e mulheres em períodos de resguardo. Destes, os mais importantes são: rubalo (Centropomus undecimalis, C. parallelus, entre outras espécies), curvina (Micropogonias furnieri), carapeba (Diapterus rhombeus) e muçum (Synbranchus marmoratus). Este último, apesar de sua aparência serpentiforme, foi considerado como "peixe que se pode comer tranqüilo". É interessante observar que C. undecimalis, quando atinge dimensões maiores, passa a ser denominado localmente de "rubalão". Nesse momento, passa também a ser considerado "peixe carregado". Do mesmo modo que as espécies de peixes mais evitadas são carnívoras, as espécies mais favorecidas também o são (dados obtidos junto aos informantes). Este fato discorda do que foi encontrado por Begossi (1992) e Begossi \& Braga (1992), que sustentam que a maioria dos peixes aceitos durante períodos de enfermidades alimentam-se de invertebrados ou plâncton.

De importância na interação trófico-cultural das espécies de peixes do estuário do Itapicuru são os animais classificados como "venenosos", a exemplo dos baiacus (Sphoeroides testudineus, Colomesus sp.) e do niquim (Thalassophryne nattereri). O primeiro, embora tenha sido considerado "peixe descarregado", possui utilização alimentar bastante restritiva devido ao modo como é percebido e, por isso, evitado. O segundo é geralmente consumido apenas como recurso medicinal ou por "quem tem coragem". Das duas espécies de baiacus coletadas, apenas Colomesus sp. foi considerada comestível, mas somente se esta for tratada por especialistas, pois nem todos sabem como manejá-la. O problema, segundo afirmam, é o "fel", que deve ser extraído como se segue: "corta debaixo da papada e tira a pele, o fel e a fatada" ou, "tira o couro, arranca a cabeça sem atingir o fel. Depois tira o fato com delicadeza e depois tira o fel". Quem já o provou, disse que se trata de um peixe de "carne gostosa".

A propriedade tóxica dos baiacus deve-se à tetrodotoxina (TTX) e, mais raramente, à saxitoxina (STX), neurotoxinas bloqueadoras de canais de $\mathrm{Na}^{+}$dependentes de voltagem de nervos e músculos (Oliveira \& Freitas, 1996). Estudos conduzidos por estes autores sobre a 
toxicidade em diferentes órgãos e tecidos de Lagocephalus laevigatus e Sphoeroides spengleri, demonstraram que a primeira espécie possui níveis de toxicidade não letais, enquanto que na segunda os níveis são altos. Com razão, L. laevigatus, conhecido como "pacheco", é espécie comestível no sudeste do Brasil (Oliveira \& Freitas, 1996). No Paraná, S. testudineus era comercializado em peixarias e vendido juntamente com pequenos bagres com a denominação de "cascudinho" (Joacir Stelarz Oliveira, comunicação pessoal). Casos fatais, no entanto, foram narrados no século XVII por Piso citado por Begossi (1992). No estado da Bahia, acidentes e mortes causados pela ingestão de baiacus foram registrados por Almeida \& Rocha (1989).

Além dos peixes, outros recursos pesqueiros tiveram seu consumo alimentar restringido ou ampliado, destacando-se os crustáceos e as tartarugas marinhas. Os moluscos, apesar de coletados para o comércio, não foram citados como recursos alimentares por nenhum dos informantes. Com relação aos crustáceos, observou-se que o caranguejo-gaiamum (Cardisoma guanhumi), embora seja uma espécie abundante, tem seu consumo temporariamente interditado às "mulheres paridas". Segundo os informantes, "as mulheres recém-paridas não podem comer gaiamum porque ele é um caranguejo muito carregado devido às ervas brabas (erva-de-rato, Chiococea sp., Rubiaceae) que ele come". O aratu (Coniopsis cruentata) é outra espécie com consumo restrito. Como alertam, a pessoa não deve comê-lo caso apresente ferimentos no corpo, pois sua ingestão poderia agravar o processo inflamatório, além de prolongar o tempo de cicatrização das feridas. Outras quatro espécies de caranguejos nunca são consumidos, a não ser em casos de absoluta necessidade: o grauçá (Ocypode quadrata), considerado "imundo" por comer carcaças de animais, além de apresentar um sabor adocicado; o almofada (Armases benedicti), acreditado como causador de doenças diagnosticáveis localmente, como "câncer", "tuberculose" e "fome canina"; o chama-maré (Uca maracoani) e o gaiamum-panã (Armases angustipes). Por outro lado, o caranguejo-uçá (Ucides cordatus) é considerado espécie "descarregada" sendo largamente consumido. O siri-nema ou siri-do-mangue (Callinectes exasperatus) também. O pouco consumo do siri-coceira (Callinectes marginatus), por sua vez, se dá em razão de a sua ingestão provocar comichões no corpo.

Quanto às tartarugas marinhas, quatro espécies costumavam ser amplamente utilizadas como fonte de alimentos e insumos para as populações humanas que habitavam (comunidades indígenas) ou habitam (comunidades de pescadores artesanais) o litoral norte baiano. Na Praia de Siribinha, um dos principais locais de reprodução, elas eram apanhadas especialmente durante o período reprodutivo, quando as fêmeas subiam à praia para desovar. Segundo os informantes, várias delas eram dependuradas vivas por até dois dias antes de serem abatidas. Porém, por todo a zona costeira brasileira e também no exterior, a pressão extrativista aumentou a ponto de provocar um drástico declínio no número de suas populações, o que acarretou a inclusão desses répteis na lista dos animais ameaçados de extinção (Instituto..., 1989). Antes do projeto TAMAR, era comum o consumo da carne de tartarugas e o uso do seu casco para fazer armações de óculos, pentes e enfeites (pulseiras, anéis e colares). Os ovos também eram retirados pelos habitantes locais para alimentação. A pesca às tartarugas é proibida por lei federal, a qual pune o infrator com prisão inafiançável. Essa proibição, no entanto, é um fenômeno relativamente recente e dela resultou um tabu exógeno, institucionalizado por regras que foram impostas às comunidades pelo governo e agentes conservacionistas, forçando a desconexão de uma interação Homem/animal que conta com centenas de anos.

Diversas comunidades costeiras tradicionais pescam tartarugas para sua subsistência e comércio. Os índios Miskito que vivem na costa oriental da Nicarágua, por exemplo, são muito dependentes das tartarugas verdes (Chelonia mydas) (Nietschmann, 1974). Esses répteis fornecem recursos, tais como carne, couro, óleo, casco e "calipee", uma substância gelatinosa encontrada junto à carapaça e que é a base para a sopa de tartarugas. Em Siribinha, a conexão alimentar de tartarugas faz parte da memória cultural dos moradores locais. Não obstante a proibição e o temor da ação repreensiva do Instituto Brasileiro do Meio Ambiente e dos Recursos Naturais Renováveis (IBAMA), os pescadores reagem à regra instituindo outras para quebrá-la, agindo na clandestinidade ${ }^{3}$ :

“Pegava não, matava. Matava aqui na praia. (. . .). Eles tiram os ovos e vira a tartaruga e no outro dia vai matar. Aí dá carne pra todo mundo, todo mundo comia. Eu agora não como, mas comia era muito. Até o figo (fígado) a gente comia. Era muita tartaruga mesmo. Agora que teve esse negócio que o povo tem até medo de tirar um ovo. Pegar ela pondo aí na praia não tira um ovo pra comer, porque se ver e se argum tirá, come escondidinho" (grifo meu).

(Dona Z., 90 anos).

A literatura demonstra que diferentes comunidades pesqueiras tradicionais desenvolveram, independentemente, padrões auto-reguladores e dinâmicos para um manejo sustentável de um recurso (pescado) mantido como propriedade comum (Johannes, 1978; Acheson, 1981; Hammer et al., 1993; Gottesfeld, 1994). Um desses padrões é a estratégia ecologicamente sustentável de considerar recursos faunísticos como tabus alimentares de modo que isso possa minimizar a sua

\footnotetext{
(3) O autor, inclusive, teve a chance de documentar a cena cultural na qual um espécime (Chelonia mydas ?) adulto, que media mais de um metro de comprimento e que "apareceu" morto no estuário, foi desmembrado pelos pescadores. Segundo eles, a tartaruga havia sofrido uma mordida de um cação na "aba" (nadadeira) direita e estava desfalecida há algumas horas. Na ocasião, alguns pescadores, desconfiados com minha presença, perguntaram-me se eu trabalhava para o IBAMA. Mesmo assim, a carne (para consumo) e a banha (para remédio) foram coletadas.
} 
superexploração (Ross, 1978; Posey, 1987). A administração racional (conservação) de recursos biológicos baseia-se efetivamente no conhecimento de utilidade funcional e está institucionalizada na forma de tabus. Por meio de uma revisão bibliográfica, Colding \& Folke (1997) encontraram cerca de 70 exemplos de tabus do tipo espécie-específico. Destes, 30\% relacionavam-se a espécies ameaçadas de extinção registradas pela União Internacional para a Conservação da Natureza.

Segundo a interpretação de alguns teóricos, a restrição ao consumo de pescado pode estar baseada em critérios ideológicos ou em razões materialistas (Begossi 1992). Em comunidades pesqueiras brasileiras, o tema tem sido abordado através das perspectivas utilitária e estrutural, recorrendo-se tanto aos aspectos do ambiente, tais como ecologia trófica, toxicidade e uso medicinal de peixes, quanto às percepções que os pescadores têm sobre os mesmos, como seu comportamento, odor, entre outros (Begossi, 1992). Segundo Marques (1991), o papel do homem é culturalmente mediado e isto reflete-se mentalmente na instituição de regras que restringem ou incrementam o consumo alimentar do pescado e, comportamentalmente, no cumprimento dessas regras e na manipulação das cadeias alimentares. Em outro texto, o autor afirma que, muitas vezes, não são em simples cadeias tróficas que o homem insere-se como elo conectado aos peixes; com freqüência, ele diz, tecem-se complexas redes em que cadeias trófico-culturais contribuem de forma acentuada para a sua configuração (Marques, 1995).

Pesquisadores reconhecem agora que os aspectos sócio-culturais das comunidades devem ser considerados em todas as discussões sobre desenvolvimento sustentável (Morin-Labatut \& Akhtar, 1992; Agrawal, 1995; Zwahlen, 1996; Posey, 1997; Sachs, 1997). Esta perspectiva social inclui o modo como os povos percebem, utilizam, alocam, transferem e manejam seus recursos naturais (Johannes, 1993). Assim, discutir as relações que existem entre as disponibilidades ofertadas pelo meio, sua utilização alimentar, as conseqüências fisiológicas em decorrência de seu consumo e as estruturas econômicas e sociais que as suportam dentro da multidimensionalidade do desenvolvimento sustentável traduz-se como um dos elementos fundamentais para se chegar à sustentabilidade, uma vez que "a dieta importa para a sustentabilidade ambiental" (Goodland, 1997).

\section{REFERÊNCIAS BIBLIOGRÁFICAS}

ACHESON, J.M. Anthropology of fishing. Annual Review of Anthropology, Palo Alto, v.10, p.275-316, 1981.

AGRAWAL, A. Indigenous and scientific knowledge: some critical comments. Indigenous Knowledge \& Development Monitor, Holanda, v.3, n.3, p.1-10, 1995.
ALMEIDA, V.G., ROCHA, C.M. Registros de acidentes com peixes peçonhentos e/ou venenosos. Revista da Sociedade Brasileira de Toxicologia, v.2, n.1, p.49-51, 1989.

BAHIA. Governo do Estado da Bahia Secretaria de Agricultura. Perfil do setor pesqueiro. Salvador, 1994. 79p.

BAHUCHET, S. Ethnoécologie. [online] 1997. Available from WWW.URL:http://lucy.ukc.ac.uk/Sonja/RF/Dividocs/ Ethnoecologie_S._Bahuchet.htm. [cited 6-2-1998].

BEGOSSI, A., PETRERE JR., M. Utilização de recursos aquáticos e tecnologia entre pescadores do Médio Tocantins (GO e MA). In: ENCONTRO DE CIÊNCIAS SOCIAIS E O MAR NO BRASIL, 2., 1988, São Paulo. Coletânea de trabalhos apresentados. São Paulo : IOUSP/F.FORD/UICN, 1988. p.158-169.

BEGOSSI, A. Food taboos at Búzios Island (Brazil): their significance and relation to folk medicine. Journal of Ethnobiology, Washington DC, v.12, n.1, p.117-139, 1992.

BEGOSSI, A., BRAGA, F.M.S. Food taboos and folk medicine among fishermen from the Tocantins River (Brazil). Amazoniana, Manaus, v.12, p.101-118, 1992.

BULMER, R.N., MENZIES, J.I., PARKER, F. Karam classification of reptiles and fishes. Journal of the Polynesian Society, Auckland, v.84, p.267-308, 1975.

CASTELO BRANCO, P., BEGOSSI, A. Escolha e consumo de itens animais em uma vila de pescadores do Rio Piracicaba (SP). In: CONGRESSO DE ECOLOGIA DO BRASIL, 3., 1996, Brasília (DF). Resumos. Brasília : Universidade de Brasília, 1996, p.241.

CENTRO DE ESTATÍSTICA E INFORMAÇÕES (Bahia). Informações básicas dos municípios baianos: região litoral norte. Salvador: Governo do Estado da Bahia, 1994. 320p.

COLDING, J., FOLKE, C. The relations among threatened species, their protection, and taboos. Conservation ecology, v.1, n.1, p.6, 1997. [online]. Available from WWW.URL:http:// www.consecol.org/vol1/iss1/art6. [cited 28-7-1998].

GOODLAND, R. Sustentabilidade ambiental: comer melhor e matar menos. In: CAVALCANTI, C. Meio ambiente, desenvolvimento sustentável e políticas públicas. São Paulo : Cortez; 1997. p.271-298.

GOTTESFELD, L.M.J. Conservation, territory, and traditional beliefs: an analysis of Gitksan and Wet'suwet'en subsistence, Northwest British Columbia, Canada. Human Ecology, New York, v.22, p.433-465, 1994.

HAMMER, M., JANSSON, A., JANSSON, B. Diversity change and sustainability: implications for fisheries. Ambio, Estocolmo, v.22, n.2/3, p.97-105, 1993.

HYNDMAN, D.C. Hunting and the classification of game animals among the Wopkaimin. Oceania, Sydney, v.54, n.4, p.289-309, 1984.

INSTITUTO BRASILEIRO DO MEIO AMBIENTE E DOS RECURSOS NATURAIS RENOVÁVEIS. Lista oficial da fauna ameaçada de extinção no Brasil. Brasília, 1989. 65p.

JOHANNES, R.E. Integrating traditional ecological knowledge and management with environmental impact assessment. In: INGLIS, J.T. Traditional ecological knowledge: concepts and cases. Ottawa : International Program on Traditional Ecological Knowledge and International Development Research Centre, 1993. p.33-39. 
JOHANNES, R.E. Traditional marine conservation methods in Oceania and their demise. Annual Review of Ecological Systems, Palo Alto, v.9, p.349-364, 1978.

MADI, E.F., BEGOSSI, A. Uso dos pescado pelas famílias moradoras da Rua do Porto, Piracicaba (SP). In: SIMPÓSIO DE ETNOBIOLOGIA E ETNOECOLOGIA, 1., 1996, Feira de Santana. Resumos... Feira de Santana : Universidade Estadual de Feira de Santana, 1996. p.23.

MARQUES, J.G.W. Aspectos ecológicos na etnoictiologia dos pescadores do Complexo Estuarino-lagunar Mundaú-Manguaba. Campinas, 1991. 292p. Tese (Doutorado em Ecologia) - Universidade Estadual de Campinas, 1991.

MARQUES, J.G.W. Pescando pescadores. Etnoecologia abrangente no baixo São Francisco. São Paulo : NUPAUB-USP, 1995. 285p.

MITCHELL, B. Geography and resource analyses. 2.ed. London : Longman Scientific and Technical, 1989. 245p.

MORÁN, E.F. A ecologia humana das populações da Amazônia. Petrópolis : Vozes, 1990. 234p.

MORIN-LABATUT, G., AKHTAR, S. Traditional environmental knowledge: a resource to manage and share. Journal of the Society for International Development, Roma, v.4, p.24-30, 1992.

MOYLE, P.B., CECH JR., J. Fishes: an introduction to ichthyology. 3.ed. New Jersey: Prentice Hall, 1996. 412p.

MURRIETA, R. O dilema do papa-chibé: consumo alimentar, nutrição e práticas de intervenção na Ilha de Ituqui, baixo Amazonas, Pará. Revista de Antropologia, Belém, v.41, n.1, p.97-150, 1998.

NIETSCHMANN, B. When the turtle collapses, the world ends. Natural History, New York, v.83, p.34-43, 1974.

NORSE, E.A. Global marine biological diversity: a strategy for building conservation into decision making. Washington DC : Island Press, 1993. 383p.

OLIVEIRA, J.S., FREITAS, J.C. Toxicidade de peixes tetraodontídeos (Osteichthyes, Teleostei): dados preliminares. In: SIMPÓSIO DE BIOLOGIA MARINHA, 11., 1996, São Sebastião. Resumos. São Sebastião: Sociedade Brasileira de Ictiologia, 1996. p.34.
PETRERE JR, M. Nota sobre a pesca dos índios Kayapó da aldeia de Gorotire, Rio Fresco, Pará. Boletim do Museu Paraense Emílio Goeldi, Série Antropologia, Belém, v.6, n.1, p.5-17, 1990.

POSEY, D.A. Etnobiologia e ciência de folk: sua importância para a Amazônia. Tübinger Geographische Studien, Tübingen, v.95, p.95-108, 1987.

POSEY, D.A. Exploração da biodiversidade e do conhecimento indígena na América Latina: desafios à soberania e à velha ordem. In: CAVALCANTI, C. Meio ambiente, desenvolvimento sustentável e políticas públicas. São Paulo : Cortez, 1997. p.345-368.

ROSS, E.B. Food taboos, diet, and hunting strategy: the adaptation to animals in Amazon cultural ecology. Current Anthropology, Chicago, v.19, p.1-36, 1978.

ROYERO, R. Contribución al conocimiento de la etnoictiología Piaroa (Dearuwa). Antropologica, Caracas, v.72, p.61-75, 1989.

SACHS, I. A cooperação Sul-Sul e o desenvolvimento sustentável nos trópicos úmidos. In: ARAGÓN, L.E., CLÜSENER-GODT, M. Reservas da biosfera e reservas extrativistas: conservação da biodiversidade e ecodesenvolvimento. Belém : Associação das Universidades Amazônicas,1997. p.1-8.

SIMOONS, F.J. Traditional use and avoidance of foods of animal origin: a culture historical view. BioScience, Washington DC, v.28, n.3, p.178-184, 1978.

SMITH, N.J.H. The impact of cultural and ecological change on Amazonian fisheries. Biological Conservation, Essex, v.32, p.355-373, 1985.

VAN VELTHEM, L.H. Os Wayana, as águas, os peixes e a pesca. Boletim Museu Paraense Emílio Goeldi, Série Antropolologia, Belém, v.6, n.1, p.107-116, 1990.

ZWAHLEN, R. Traditional methods: a guarantee for sustainability? Indigenous Knowledge \& Development Monitor, v.4, n.3, p.1-7, 1996.

Recebido para publicação em 1 de fevereiro e aceito em 15 de junho de 1999. 